\title{
PROJETO DE EXTENSÃO "ENSINANDO A SALVAR VIDAS": UM RELATO DE EXPERIÊNCIA NA PANDEMIA
}

\section{THE EXTENTION PROJECT "TEACHING HOW TO SAVE LIVES": AN EXPERIENCE REPORT IN PANDEMIC TIME}

\author{
Samuel Marques dos Reis* \\ ORCID: https://orcid.org/0000-0002-8998-6050 \\ Gabriel Silvestre Minucci** \\ ORCID: https://orcid.org/0000-0001-5446-647X \\ Mirian Diená Pastorini Jurgilas*** \\ ORCID: https://orcid.org/0000-0002-6783-4996 \\ Milena Oliveira Moreira**** \\ ORCID: https://orcid.org/0000-0002-0469-4877 \\ Aline Rezende de Oliveira***** \\ ORCID: https://orcid.org/0000-0001-6878-9261
}

\section{Resumo}

Dentre as maiores causas de óbito no Brasil, figuram as que possuem como desfecho final a parada cardiorrespiratória, a qual ainda representa e permanece como um dos maiores problemas de saúde em nível mundial. Estimativas apontam que ocorram cerca de 200 mil paradas cardiorrespiratórias anualmente no Brasil, sendo que metade ocorre em ambiente extra-hospitalar, dependendo, assim, da ação de cidadãos leigos. Este artigo tem como objetivo relatar as experiências com o Projeto de Extensão "Ensinando a Salvar Vidas", realizado para capacitar e ampliar os conhecimentos da população a respeito das práticas de ressuscitação cardiopulmonar, por meio de intervenções teórico-práticas nas escolas de São João del-Rei. Entretanto, devido à pandemia do vírus SARS-CoV-2, o projeto sofreu alterações nos seus planos e metodologias iniciais, sem a possibilidade dos encontros presenciais. Foram adotadas estratégias de ensino a distância, com o intuito de se manterem os objetivos do projeto, entendendo-se a importância das intervenções.

Palavras-chave: Relações comunidade-instituição; Educação em saúde; Parada cardíaca; Reanimação cardiopulmonar.

\begin{abstract}
Among the major causes of death in Brazil, there are those that have cardiorespiratory arrest as final outcome. It still represents and remains one of the biggest health problems worldwide. Estimates indicate that about 200,000 cardiopulmonary arrests occur annually in Brazil, half of which occur outside the hospital, thus depending on the action of lay citizens. This article aims to report the experiences of the "Teaching to Save Lives" Extention Project, designed to train and broaden the population's knowledge about cardiopulmonary resuscitation practices, through theoretical-practical interventions in schools of São João del Rei. However, without the possibility of face-to-face meetings due to the SARS-CoV-2 virus pandemic, the project was called upon to rethink its plans and methodologies. Understanding the importance of the interventions, distance learning strategies were adopted in order to maintain the objectives of the project.
\end{abstract}

Keywords: Community-Institutional relations; Health education; Heart arrest; Cardiopulmonary resuscitation.

Data recebimento: $15 / 12 / 2020$

\footnotetext{
* Aluno de Graduação da Universidade Federal de São João del Rei (UFSJ), São João del Rei - MG, Brasil. E-mail: smdrsamuel@gmail.com ** Aluno de Graduação da Universidade Federal de São João del Rei (UFSJ), São João del Rei - MG, Brasil. E-mail: gabrielsilcci@gmail.com *** Professora da Universidade Federal de São João del Rei (UFSJ), São João del Rei - MG, Brasil. E-mail: mirianjurgilas@ufsj.edu.br **** Aluna de Graduação da Universidade Federal de São João del Rei (UFSJ), São João del Rei - MG, Brasil. E-mail: milena.oliveira2199@gmail.com ***** Aluna de Graduação da Universidade Federal de São João del Rei (UFSJ), São João del Rei - MG, Brasil. E-mail: alinerezendetecn@hotmail.com
} 


\section{Introdução}

Dentre as maiores causas de óbito no Brasil, as doenças isquêmicas do coração ganham destaque, principalmente o infarto agudo do miocárdio, causador de, pelo menos, $85 \%$ das paradas cardiorrespiratórias (PCR). Esse fato é decorrente de diversos motivos, como a transição demográfica do país, com o aumento da população de idosos; o crescimento na prevalência do sedentarismo e da obesidade; o maior consumo de gorduras e a redução da ingestão de frutas e de verduras; o uso de bebidas alcoólicas em excesso e o tabagismo. Entre outras causas igualmente envolvidas com a incidência de paradas cardiorrespiratórias, tem-se a exposição aos fatores de risco associados às doenças do sistema circulatório, principalmente a hipertensão arterial sistêmica, a realidade das condições socioeconômicas no país e as dificuldades no acesso à saúde (BRANT et al., 2017; BERNOCHE et al., 2019; GONZALEZ, 2013; SANTOS et al., 2018).

A PCR é definida como o cessar da atividade mecânica do coração, apresentando ausência de pulso detectável, irresponsividade e apneia ou respiração agônica (JACOBS, 2004). Ela ainda representa e permanece como um dos maiores problemas de saúde em nível mundial. Estima-se que aproximadamente 200 mil casos ocorram anualmente no Brasil, sendo que metade desse número ocorre em ambiente hospitalar, enquanto a outra parte em ambientes extra-hospitalares, como aeroportos, residências, shoppings, estádios, casas de repouso de idosos, empresas, entre outros. Segundo a American Heart Association, a mortalidade de pacientes fora do hospital poderia ser reduzida se a população fosse apta para realizar as manobras de ressuscitação cardiopulmonar (RCP), um conjunto de técnicas que visam manter as funções circulatórias e respiratórias. Entretanto, grande parte dos cidadãos desconhece ou não domina os fundamentos e as práticas necessárias para a sua realização (MALTA, 2020).

Nesse sentido, torna-se imprescindível a promoção de iniciativas com a finalidade de educar e de orientar sobre o reconhecimento de parada cardiorrespiratória e a realização das manobras de ressuscitação cardiopulmonar. Esse conhecimento deve ser difundido com o objetivo de capacitar a população a socorrer eficazmente vítimas de parada cardiorrespiratória, aumentando, assim, significativamente as taxas de sobrevivência em casos que ocorrem em ambiente extra-hospitalar e sem a presença de profissional de saúde devidamente treinado.

Com relação ao ensino e ao aprendizado sobre RCP, o público infantil e adolescente é tão importante quanto o público adulto. A declaração "Kids Save Lives", criada pela Fundação Europeia para Segurança do Paciente, o Conselho Europeu de Ressuscitação, o Comitê Internacional de Ressuscitação e a Federação Mundial de Sociedades de Anestesiologia, e incentivada pela Organização Mundial da Saúde (OMS), estabelece diretrizes capazes de auxiliar nesse processo. Segundo a Declaração, o público jovem é considerado como potência na multiplicação do conhecimento adquirido, difundindo para amigos, familiares e conhecidos; tem alta capacidade de entendimento e de apreensão dos ensinamentos sobre parada cardiorrespiratória e ressuscitação cardiopulmonar, além de apresentar menor chance de hesitar ou ter receio de prestar socorro quando necessário (BÖTTIGER; VAN AKEN, 2015).

Segundo a Política Nacional de Extensão Universitária, a extensão tem papel fundamental na identificação e na transformação de problemas e de carências presentes nos diversos setores 
da sociedade, incluindo a saúde (FORPROEX, 2012). Nesse sentido, em 2019, foi proposto o Projeto de Extensão "Ensinando a salvar vidas", vinculado ao curso de Medicina da Universidade Federal de São João Del Rei (UFSJ), Campus Dom Bosco, com a participação de docente como orientadora e discentes como membros voluntários. O objetivo principal do projeto é ampliar a parcela da população jovem da cidade de São João del-Rei (MG) com capacidade de identificar uma parada cardiorrespiratória e realizar efetivamente as manobras de ressuscitação cardiopulmonar.

Tinha-se, como metodologia inicial, intervenções presenciais teórico-práticas com estudantes das escolas da cidade. Contudo, diante da realidade imposta pelo período de pandemia do vírus SARS-CoV-2 e a necessidade de adoção de medidas de segurança, as ações de extensão universitária presenciais tornaram-se impraticáveis, e fez-se necessário repensar e adaptar as formas de trabalho (MARQUES, 2020). Assim, o Projeto "Ensinando a Salvar Vidas" também precisou adaptar suas atividades, visando manter sua proposta principal e as intervenções, sendo convocado a reconsiderar suas estratégias e metodologias sem a possibilidade dos encontros presenciais com a população.

Desse modo, o presente estudo tem como objetivo geral relatar as experiências com o Projeto de Extensão "Ensinando a Salvar Vidas", realizado para capacitar e ampliar os conhecimentos da população a respeito das práticas de ressuscitação cardiopulmonar, por meio de intervenções teórico-práticas nas escolas de São João del-Rei. E tem como objetivos específicos apresentar o planejamento inicial e as adaptações sofridas ao longo da realização devido ao período de pandemia, além de discutir a adesão das escolas participantes, os fatores que dificultaram e facilitaram a implementação do projeto e as vivências dos seus integrantes.

\section{Metodologia}

O projeto de Extensão "Ensinando a salvar vidas" foi aprovado pelo Programa Institucional de Bolsas de Extensão (PIBEX) - EDITAL Nº09/2019/UFSJ/PROEX, e tem como objetivo principal o ensino de suporte básico de vida a estudantes de escolas das redes pública e privada da cidade de São João Del Rei. Foi elaborado e escrito entre setembro e outubro de 2019, e aprovado em edital PIBEX em dezembro, com início em abril de 2020 e término previsto para junho de 2021.

Definiu-se a participação de estudantes cursando, atualmente, o sétimo, oitavo ou nono ano do Ensino Fundamental, e o primeiro ou segundo ano do Ensino Médio. A escolha foi justificada pela declaração "Kids save lives", aprovada pela OMS em 2015, que recomenda oferecer treinamento anual a partir dos 12 anos de idade. (BÖTTIGER; VAN AKEN, 2015).

Durante a elaboração do projeto, em 2019, foram construídas quatro etapas principais. Devido à pandemia, essas etapas foram mantidas, porém, adaptadas para ocorrer à distância. 
Na primeira etapa, foi proposta a realização de revisões bibliográficas e de reuniões presenciais para estudo e treinamento dos discentes extensionistas em relação à $\mathrm{PCR}$, à prática de RCP e às metodologias pedagógicas para o ensino desses conhecimentos para crianças e adolescentes. Além disso, foi realizado o contato com as escolas de São João del Rei para verificar interesse de participação e a assinatura de Termo de Concordância pelos gestores.

Na segunda etapa, foi idealizada a confecção de panfletos educativos e a construção das atividades para as intervenções presenciais. As atividades delineadas foram aulas presenciais teórico-práticas em que seriam ministrados conteúdos referentes a conceitos gerais, identificação de PCR, aprendizado e preparo para realização de RCP, e treinamento em manequins. Ao início e ao fim da intervenção, seria aplicado questionário sobre os conhecimentos gerais sobre PCR e RCP, com o intuito de avaliar o impacto da intervenção. Além disso, a assinatura de Termos de Assentimento Livre e Esclarecido e de Consentimento Livre e Esclarecido por alunos e seus responsáveis.

Em terceira fase, planejou-se a realização das intervenções presenciais nas escolas participantes. E, na última etapa, a análise dos dados obtidos por meio dos questionários e a escrita de artigos científicos. Para viabilizar a realização do projeto à distância, diversas medidas foram tomadas para garantir a qualidade e a efetividade das atividades mediante às condições impostas pela pandemia. No momento atual, o projeto está na terceira fase, com a participação de quatro escolas.

Com relação às adaptações da primeira etapa, as reuniões presenciais para estudo e treinamento dos discentes ocorreram de forma remota, com o auxílio da plataforma "Google Meet". As escolas foram contatadas por meio de telefonemas e os termos de concordância enviados por e-mail para que fossem assinados pelos gestores. Quatro escolas concordaram em participar do projeto de forma remota, sendo as escolas 1, 2 e 3 públicas e a escola 4 de ensino privado.

Na segunda etapa, adaptaram-se os Termos de Assentimento Livre e Esclarecido e de Consentimento Livre e Esclarecido para serem lidos e assinados por meio de formulários online na plataforma "Google Forms". Os questionários que seriam preenchidos com papel e caneta pelos estudantes também foram adaptados para serem disponibilizados em formulário na mesma plataforma, como mostrado na Figura 1. As aulas teórico-práticas que ocorreriam presencialmente nas escolas foram gravadas e disponibilizadas em formato de videoaula. A Figura 2 ilustra a abertura de uma videoaula produzida, enquanto a Figura 3 mostra trecho de videoaula em que um extensionista ensina a reconhecer a PCR e a realizar a RCP com auxílio de um manequim. 
Figura 1 - Início do questionário disponibilizado na plataforma "Google Forms"

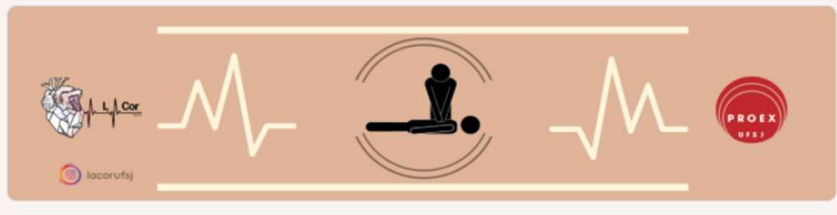

\section{Questionário sobre Ressuscitação}

Cardiopulmonar - INICIAL

Olá!

Elaboramos as perguntas que se seguem com o intuito de avaliar os conhecimentos prévios

e os adquiridos após a realização do projeto!

Agradecemos a sua participação : )

*Obrigatório

Informações Gerais

Antes de responder às perguntas sobre as técnicas de ressuscitação cardiopulmonar, preencha e/ou

responda as questöes abaixo!

Data de Hoje *

Data

$\mathrm{dd} / \mathrm{mm} / \mathrm{aaa}: \quad \square$

Fonte: Os autores

Figura 2 - Capa de videoaula confeccionadas para a intervenção

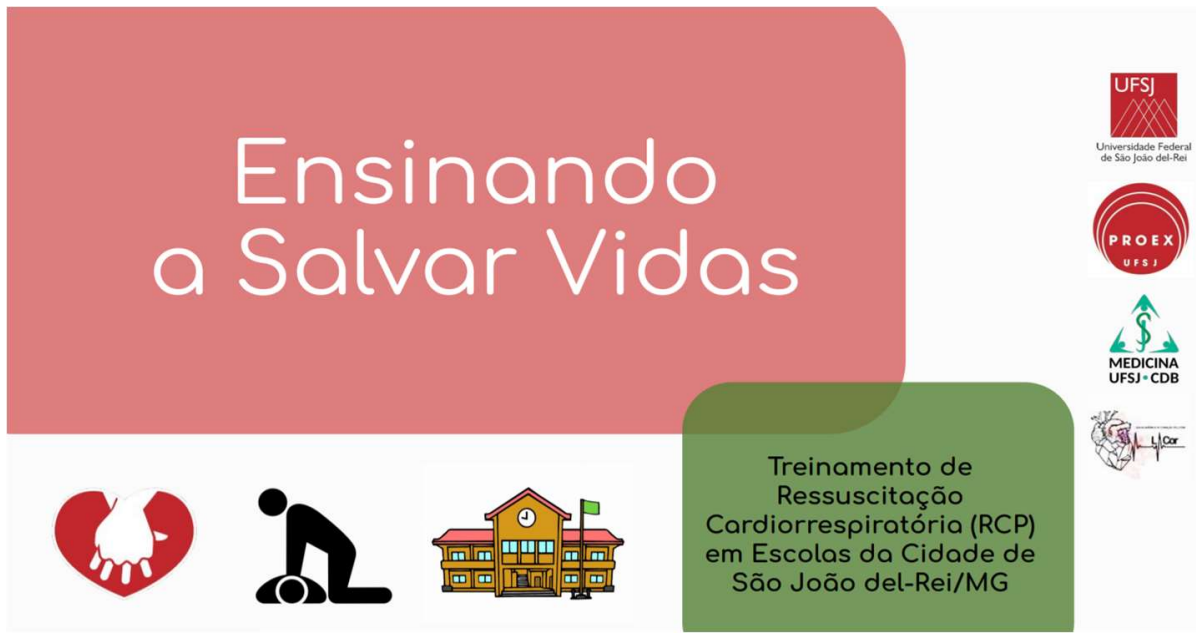

Fonte: Os autores 
A terceira etapa, que consiste na intervenção com os alunos, foi adaptada para ocorrer de forma online. Utilizaram-se as plataformas 'Google Class", sendo que as videoaulas e questionários foram disponibilizados em ordem correta e data preestabelecidas com cada escola, e "Google meet" para reunião e orientação dos alunos para realizar as atividades.

Figura 3 - Trecho da videoaula em que extensionista demonstra as manobras de RCP em manequim

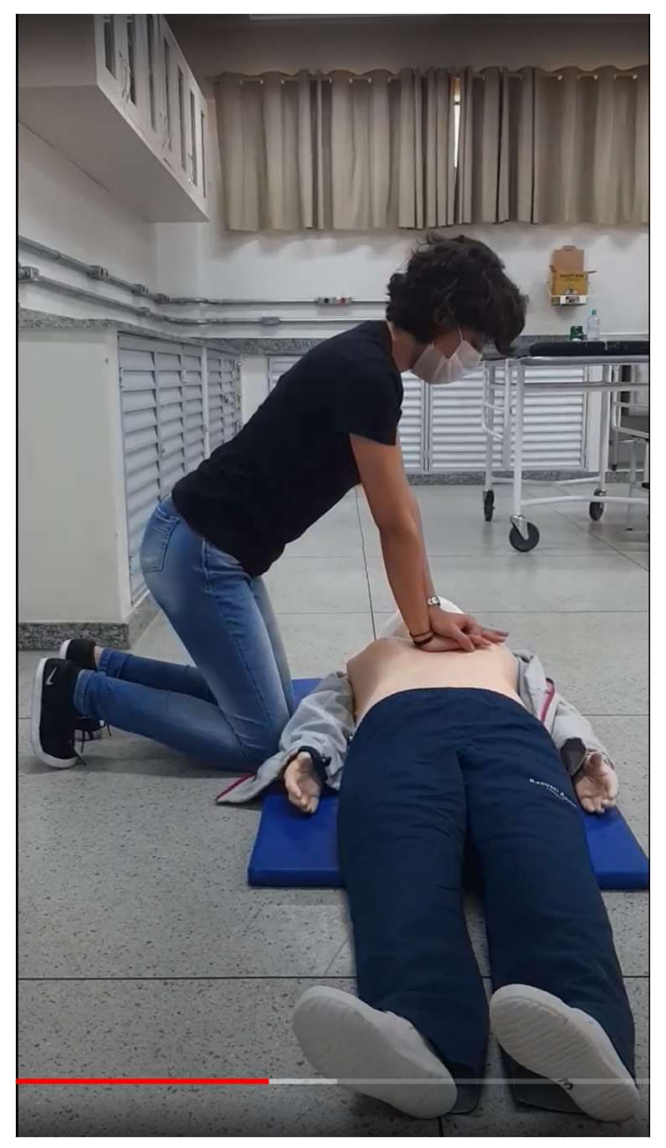

Fonte: Os autores

O relato de experiência é um método de pesquisa descritiva que propõe reflexões sobre uma experiência que possam contribuir para a construção de conhecimento em alguma área de atuação de interesse científico e destaca-se como resultante de algo processual e narrativo. Este relato é um resultado parcial do projeto de extensão destacado, com objetivos e resultados próprios. Segundo as diretrizes para pesquisas definidas pelas Resoluções CNS/MS 196/96 e 510/16 e todas suas complementares, a pesquisa não necessitou da submissão para apreciação 
ética, por referir-se a um relato de experiência da própria equipe de extensão, em concordância com os locais onde ocorreram as intervenções e com garantias de confidencialidade dos dados e dos participantes envolvidos.

\section{Resultados}

Até o presente momento, foram realizadas intervenções nas quatro escolas de São João del Rei contempladas pelo projeto e foram convidados 541 alunos.

A principal dificuldade encontrada foi assegurar a aderência dos estudantes, pois as taxas de adesão foram abaixo do esperado. Dentre as demais escolas, a escola 4, pertencente à rede privada, apresentou a maior aderência. Considerando o total de alunos que foram convidados a participar, apenas 143 estudantes concluíram todas as atividades propostas, resultando em taxa de adesão total próxima de $26 \%$. Esses dados podem ser observados na Tabela 1.

Tabela 1 - Taxa de adesão de acordo com cada escola e o somatório total de alunos.

\begin{tabular}{|c|c|c|}
\hline Instituição & Adesão & Adesão em porcentagem \\
\hline Escola 1 (rede pública) & $13 / 234$ & $5,55 \%$ \\
\hline Escola 2 (rede pública) & $20 / 119$ & $12 \%$ \\
\hline Escola 3 (rede pública) & $23 / 53$ & $43,39 \%$ \\
\hline Escola 4 (rede privada) & & $64,44 \%$ \\
\hline Somatório & $87 / 135$ & $26,43 \%$ \\
\hline
\end{tabular}

Fonte: Os autores

Observou-se como possíveis fatores que influenciaram na adesão o acesso precário a dispositivos eletrônicos e à internet, a sobrecarga de atividades escolares obrigatórias e a realização da intervenção em ambiente digital.

Um grande desafio encontrado foi a elaboração das intervenções à distância, pois foi necessário adaptar as práticas educativas idealizadas inicialmente para que pudessem romper com os modelos tradicionais e presenciais de interação. Para isso, foram produzidos materiais audiovisuais educativos com potencial de serem facilmente compreendidos e buscadas plataformas digitais gratuitas e acessíveis que permitissem a participação dos alunos através de celulares, tablets e computadores. Outra dificuldade identificada foi a comunicação com as escolas, uma vez que essas se encontravam com horário de funcionamento reduzido. Isso lentificou o estabelecimento de contato inicial com os gestores, exigindo inúmeros telefonemas e e-mails.

Por outro lado, após contato inicial, evidenciou-se como facilidade grande solicitude dos gestores e professores em todas as escolas participantes. Ambos tiveram papel essencial ao promoverem a participação e ao supervisionarem os alunos durante a realização das atividades propostas na intervenção. Outra facilidade foi o engajamento e o interesse demonstrados 
por parte dos estudantes, sobretudo os que concluíram todas as atividades. As perguntas, os comentários e as colaborações feitas por eles durante as intervenções educativas auxiliaram os acadêmicos a conduzirem um momento com maior troca de saberes e mais aprendizados. Além disso, as plataformas digitais utilizadas, disponíveis gratuitamente, foram primordiais para garantir o encontro e a interação entre acadêmicos e participantes.

De forma geral, também foi possível observar a construção de conhecimento dos escolares envolvidos, como o proposto pelo projeto. Diversos estudantes manifestaram não saber o que era ou como fazer uma massagem cardíaca inicialmente e, ao final do processo, vislumbravamse os alunos trocando experiências de aprendizado a partir das intervenções realizadas, manifestando dúvidas mais embasadas sobre o tema e o interesse em compartilhar com colegas de outras turmas o que entenderam, inclusive convidando a equipe para mais abordagens semelhantes àquelas. Além disso, evidenciou-se melhora qualitativa e quantitativa nas respostas dos alunos aos questionários, reforçando o impacto da aprendizagem das intervenções realizadas pelo projeto "Ensinando a salvar vidas".

\section{Discussão}

Os temas relativos à PCR e a RCP referem-se à área de Urgência e Emergência (UE), que é um importante tema na formação do profissional de saúde, reforçada pela própria Organização Mundial da Saúde (OMS) como fundamental na trajetória de construção acadêmica do médico (SORTE et al., 2020). A principal causa de atendimento pelos serviços de Emergência são os ritmos cardíacos característicos de PCR e situações como politrauma e infarto agudo do miocárdio, em que todos exigem reconhecimento e intervenção imediatos para o prognóstico do paciente. Em 2013, a Lei no 12.871 passou a exigir que, na graduação de Medicina, houvesse caga horária destinada aos serviços de UE, reconhecendo a importância do Suporte de Vida para o conhecimento prático do profissional, além de o campo oferecer experiências educacionais únicas para os estudantes de medicina (PEREIRA JÚNIOR et al., 2015; SORTE et al., 2020).

Considerando o curso de Medicina da Universidade Federal de São João del Rei, os acadêmicos são expostos logo no segundo período ao suporte básico de vida, na disciplina Urgência e Emergência, e aprofundados ao longo de todo o ciclo clínico e do internato. Este projeto de extensão surgiu da convicção da importância da ampliação dos conhecimentos a toda a população acadêmica ou não, aprimorando conhecimentos dos estudantes e dos docentes e compondo-os com outros públicos, permitindo espaços de reflexão e de produção de conhecimentos que favorecessem que mais pessoas pudessem ser salvas em cenas de risco que demandem tais saberes.

Assim, as atividades propostas tinham também como intenção compartilhar o conhecimento sobre parada cardiorrespiratória e ressuscitação cardiopulmonar com os estudantes, capacitando-os para a realização das manobras em situações necessárias, vendo-os como sujeitos capazes de realizar os passos com efetividade. Também tem-se como intenção, a partir 
da abordagem, acionar as capacidades desses indivíduos como multiplicadores e disseminadores de conhecimentos dentro de seus lares e de seus nichos sociais.

Alguns autores explicitam a importância de tratar no ensino básico aspectos como primeiros socorros ou parada cardiorrespiratória, tendo a ação com os escolares a capacidade de influenciar culturalmente o manejo nessas situações ao favorecer a prestação de socorro e a diminuição de óbitos e sequelas. A exposição durante os anos escolares favorece a solidificação do aprendizado e aumenta, assim, as chances de o indivíduo ser capaz de agir corretamente (MATOS; SOUZA; ALVES, 2016; MESQUITA et al., 2017).

As intervenções com escolares a respeito de RCP tem grande impacto na formação dos alunos enquanto cidadãos ativos em situações que demandam conhecimentos práticos sobre as manobras de ressuscitação. Diversos autores descrevem o conhecimento incipiente dos alunos antes das intervenções e os ganhos imediatos e seis meses após o ensino teóricoprático no contexto de PCR e Primeiros Socorros (CHAVES et al., 2017; MESQUITA et al., 2017; SILVA, 2019).

Mesmo com as limitações físicas inerentes à idade, ao peso e à estatura, que podem comprometer a eficácia da técnica de ressuscitação cardiopulmonar, estudantes da faixa etária contemplada mostram-se mais interessados e comprometidos com o assunto e, por isso, têm sua relevância na declaração "Kids Save Lives", contribuindo para a diminuição de óbitos e sequelas decorrentes da PCR. (BARBOSA; SANTANA; NICOLINI, 2020; MATOS, SOUZA, ALVES, 2016).

Além disso, o campo do ensino, no ano de 2020, foi marcado pelo momento histórico da pandemia do vírus SARS-CoV-2. Esse período também foi vivenciado pelo projeto, que se inseria nas práticas pedagógicas por envolver-se nas escolas do município de São João delRei. Nesse momento, o isolamento social, a limitação de acesso a recursos, o funcionamento de serviços em horário reduzido, o trabalho remoto, a tecnologia mediando o processo de ensino-aprendizagem e as desigualdades no acesso e no uso das tecnologias foram fatores que se fizeram pesar e pensar sobre novas práticas e modelos de ensino, capazes de proporcionar aos alunos as possibilidades de interação e, realmente, incluí-los no processo de aprendizado. (VALLE; MARCOM, 2020)

A literatura já aponta que a dificuldade de adesão dos alunos às atividades remotas se dá, principalmente, pela dificuldade no acesso às tecnologias e aos conhecimentos técnicos básicos, os quais estão diretamente associados à desigualdade social e à exclusão tecnológica. Esses aspectos atravessam tanto os conhecimentos e habilidades recrutadas para acesso a equipamentos digitais quanto o letramento e manuseio de plataformas e serviços digitais (SILVA et al., 2020). Consequentemente, tais fatores esbarram e justificam alguns resultados nas atividades propostas pelo projeto "Ensinando a Salvar Vidas", como a maior adesão dos alunos da rede privada às atividades virtuais.

Diversos estudos já tentaram avaliar o ensino do RCP entre formato de ensino teórico e teórico-prático e analisar a efetividade do treinamento tanto em leigos quanto em profissionais. A 
maioria dos resultados demonstra que não há diferença entre as duas abordagens, que a função cognitiva envolvida na realização de uma RCP eficaz não depende da exposição à prática e que o ensino com vídeos de autotreinamento tem resultados superiores às exposições convencionais, mesmo quando relativo a manobras de abertura de vias aéreas, posicionamento das mãos e compressão (CARDOSO et al., 2017; MARQUES; DIAS; ARAGÃO, 2019).

\section{Considerações finais}

Durante a realização das atividades propostas pelo projeto de extensão "Ensinando a Salvar Vidas", está sendo evidenciado o alcance gradual do seu principal objetivo: propagar o conhecimento em saúde que pode salvar vidas.

Foi constatado que a adaptação do projeto, para ocorrer à distância, foi fundamental para assegurar os resultados idealizados inicialmente.

No entanto, reconhecem-se as limitações de acesso e de conhecimento sobre tecnologia e que isso pode influenciar na forma de transmissão da informação e no alcance do projeto. Seria ideal a manutenção e estímulo futuro de atividades em outras plataformas e com outros métodos pedagógicos para garantir efetividade da proposta.

Por meio das atividades, foi possível proporcionar um momento de aprendizado para os estudantes sobre a relevância e os fundamentos da parada cardiorrespiratória, bem como sobre a realização adequada da manobra de ressuscitação cardiopulmonar.

Além disso, constatam-se consideráveis benefícios aos acadêmicos, que estão aprofundando seus conhecimentos sobre o tema, aperfeiçoando suas habilidades para atuarem como educadores em saúde e sendo estimulados a lidar de maneira eficaz com as adversidades impostas pela pandemia.

\section{Referências}

BARBOSA, H.G.D.; SANTANA, L.R.; NICOLINI, E.M. Avaliação do impacto e efetividade do treinamento de crianças em suporte básico de vida: uma revisão sistemática. Revista de Medicina, São Paulo, v. 99, n. 1, p. 56-61, 2020. DOI: 10.11606/issn.16799836.v99i1p56-61. Disponível em: https://www.revistas.usp.br/revistadc/article/view/164675. Acesso em: 10 out. 2020.

BERNOCHE, C. et al. Atualização da Diretriz de Ressuscitação Cardiopulmonar e Cuidados Cardiovasculares de Emergência da Sociedade Brasileira de Cardiologia - 2019. Arquivos Brasileiros de Cardiologia, São Paulo, v. 113, n. 3, p. 449-663, 2019. 
BÖTTIGER, B. W.; VAN AKEN, H. Kids save lives - Training school children in cardiopulmonary resuscitation worldwide is now endorsed by the World Health Organization (WHO).

Resuscitation, v. 94, n. 1, p. 5-7, 2015. DOI: 10.1016/j.resuscitation.2015.07.005. Disponível em: https://pubmed.ncbi.nlm.nih.gov/26209417/. Acesso em: 5 out. 2020.

BRANT, L. C. C. et al. Variations and particularities in cardiovascular disease mortality in Brazil and Brazilian states in 1990 and 2015: estimates from the Global Burden of Disease.

Revista Brasileira de Epidemiologia, v. 20, p. 116-128, 2017.

CARDOSO, R. R. et al. Suporte básico de vida para leigos: uma revisão integrativa.

Revista Unimontes Científica, v. 19, n. 2, p. 158-167, 2017.

CHAVES, A. F. L. et al. Reanimação cardiopulmonar nas escolas: avaliação de estratégia educativa. Revista Expressão Católica Saúde, v. 2, n. 1, p. 65-72, 2017.

FORPROEX. Ensino de Suporte Básico de Vida para Alunos de Escolas Pública e Privada do Ensino Médio. Política Nacional de Extensão Universitária, Manaus, 2012.

JACOBS, I.; NADKARNI, V.; BAHR, J. et al. Cardiac arrest and cardiopulmonary resuscitation outcome reports: update and simplification of the Utstein templates for resuscitation registries. A statement for healthcare professionals from a task force of the international liaison committee on resuscitation (American Heart Association, European Resuscitation Council, Australian Resuscitation Council, New Zealand Resuscitation Council, Heart and Stroke Foundation of Canada, InterAmerican Heart Foundation, Resuscitation Council of Southern Africa). Resuscitation, v. 63, n. 3, p. 233-49, 2004.

MALTA, D. C. et al. Mortalidade por Doenças Cardiovasculares Segundo o Sistema de Informação sobre Mortalidade e as Estimativas do Estudo Carga Global de Doenças no Brasil, 2000-2017. Arquivos Brasileiros de Cardiologia, São Paulo, v. 101, n. 2, p. 152$160,2020$.

MARQUES, G. E. C. A Extensão Universitária no Cenário Atual da Pandemia do COVID19. Revista Práticas em Extensão, São Luís, v., n. 1, p. 42-43, 2020. Disponível em: https://ppg.revistas.uema.br/index.php/praticasemextesao/article/view/2188. Acesso em: 25 out. 2020.

MARQUES, S. C.; DIAS, D. F.; ARAGÃO, I. P. B. Estudo estatístico de conhecimento e aplicação das técnicas de RCP. Revista Fluminense de Extensão Universitária, v. 9, n. 1, p. 02-08, 2019.

MATOS, D. O. N.; SOUZA, R. S.; ALVES, S. M. Inclusão da disciplina de primeiros socorros para alunos do ensino básico. Revista Interdisciplinar, Teresina, v. 9, n. 3, p. 168-178, 2016. 
MESQUITA, T. M. et al. Recurso educativo em primeiros socorros no processo ensinoaprendizagem em crianças de uma escola pública. Revista Ciência Plural, v. 3, n. 1, p. 3550, 2017. Disponível em: https://periodicos.ufrn.br/rcp/article/view/11464. Acesso em 20 out. 2020.

SANTOS, J. et al. Mortalidade por infarto agudo do miocárdio no Brasil e suas regiões geográficas: análise do efeito da idade-período-coorte. Revista Ciência \& Saúde Coletiva, Rio de Janeiro, v. 23, n. 5, p. 1621-1634, 2018.

SILVA, R. M. F. L et al. Ressuscitação cardiopulmonar de adultos com parada cardíaca intra-hospitalar utilizando o estilo Utstein. Revista Brasileira de Terapia Intensiva, São Paulo, v. 28, n. 4, p. 427-435, Dec. 2016.

SILVA, E.S. Primeiros socorros com escolares: intervenção educativa em saúde. 2019. 74 p. Tese (Graduação em Enfermagem) $\square$ Unidade Acadêmica de Enfermagem, Universidade Federal de Campina Grande, Cajazeiras, 2019.

SILVA, A. J. F. et al. A Adesão dos alunos às atividades remotas durante a pandemia: realidades da Educação Física Escolar. Corpoconsciência, v. 24, n. 2, p. 57-70, 2020.

SORTE, E. M. S. B et al. Análise da percepção de acadêmicos sobre o ensino de urgência e emergência em curso médico. Revista Brasileira de Educação Médica, v. 44, n. 3, 2020.

PEREIRA JUNIOR, G. A. et al. O ensino de urgência e emergência de acordo com as novas Diretrizes Curriculares Nacionais e a Lei do Mais Médicos. Cadernos ABEM, v. 11, n. 1, 2015.

VALLE, P. D.; MARCOM, J. L. R. Desafios da prática pedagógica e as competências para ensinar em tempos de pandemia. In: PALÚ, J.; SCHÜTZ, J. A.; MAYER, L. (Org).

Desafios da Educação em Tempos de Pandemia. Cruz Alta: Ilustração, 2020. p. 139-154. Disponível em: http://www.sed.sc.gov.br/professores-e-gestores/30754-desafios-daeducacao-em-tempos-de-pandemia. Acesso em: 22 out. 2020. 